\title{
The challenge of improving boiling: lessons learned from a randomized controlled trial of water pasteurization and safe storage in Peru
}

\author{
K. HeITZINGER ${ }^{1 *}$, C. A. ROCHA ${ }^{2}$, R. E. QUICK ${ }^{1,3}$, S. M. MONTANO ${ }^{2,4}$, \\ D. H. TILlEY JR. ${ }^{2}$, C. N. MOCK ${ }^{1}$, A. J. CARRASCO ${ }^{5}$, R. M. CABRERA ${ }^{5}$ AND \\ S. E. HAWES ${ }^{1}$ \\ ${ }^{1}$ Department of Epidemiology, University of Washington, Seattle, WA, USA \\ ${ }^{2}$ Bacteriology Department, U.S. Naval Medical Research Unit No. 6, Callao, Peru \\ ${ }^{3}$ Waterborne Disease Prevention Branch, U.S. Centers for Disease Control and Prevention, Atlanta, GA, USA \\ ${ }^{4}$ Department of Neurology, University Of Washington, Seattle, WA, USA \\ ${ }^{5}$ Department of Environmental Health, Hospital San Juan de Dios, Ica Regional Ministry of Health, Pisco, Peru
}

Received 2 September 2015; Final revision 17 January 2016; Accepted 21 January 2016; first published online 22 February 2016

\section{SUMMARY}

Boiling is the most common method of household water treatment in developing countries; however, it is not always effectively practised. We conducted a randomized controlled trial among 210 households to assess the effectiveness of water pasteurization and safe-storage interventions in reducing Escherichia coli contamination of household drinking water in a water-boiling population in rural Peru. Households were randomized to receive either a safe-storage container or a safestorage container plus water pasteurization indicator or to a control group. During a 13-week follow-up period, households that received a safe-storage container and water pasteurization indicator did not have a significantly different prevalence of stored drinking-water contamination relative to the control group [prevalence ratio (PR) $1 \cdot 18$, 95\% confidence interval (CI) 0.92-1·52]. Similarly, receipt of a safe-storage container alone had no effect on prevalence of contamination (PR 1.02, 95\% CI 0.79-1·31). Although use of water pasteurization indicators and locally available storage containers did not increase the safety of household drinking water in this study, future research could illuminate factors that facilitate the effective use of these interventions to improve water quality and reduce the risk of waterborne disease in populations that boil drinking water.

Key words: Epidemiology, Escherichia coli (E. coli), Water (quality), Water (safe).

\section{INTRODUCTION}

In low- and middle-income countries (LMICs), diarrhoea is a leading cause of morbidity and mortality in children aged $<5$ years [1-3]. Household water treatment and safe storage are recommended as part

\footnotetext{
* Author for correspondence: Ms. K. Heitzinger, University of Washington, Department of Epidemiology, Box 357236, Seattle 98195, WA, USA.

(Email: heitzk@uw.edu)
}

of the WHO strategy to reduce diarrhoea risk [4], yet $<30 \%$ of people living in LMICs report using an effective method to treat their household drinking water [5]. Boiling is the sole method of household treatment that has reached scale in any country, as it is the only method reported by $>90 \%$ of the population in nationally representative household surveys [5]. Globally, it is also over three times more frequently practised than any other method [5]. On the basis of the demonstrated effectiveness and scalability of boiling, its improvement and expansion has been 
proposed as a potentially effective means of increasing household access to safe drinking water [6].

Despite the relatively high acceptability of boiling, the practice has a number of potential shortcomings that may limit its effectiveness and use. In the absence of safe storage and handling in the home, boiled water supplies may be recontaminated [7-9]; other drawbacks include collection time and cost of fuel $[10,11]$, risk of scalding [12-15], and, among populations that rely on biomass fuel, indoor air pollution [16] and emission of black soot, an important contributing factor to climate change $[17,18]$.

There is evidence that some of the obstacles to effective boiling can be addressed by simple technological interventions. The results of randomized trials indicate that the risk of recontamination of boiled water supplies can be reduced by the use of storage containers that prevent the introduction of hands or dipping objects [19-21], although one study found no effect [22]. A study conducted in Kenya demonstrated the feasibility and effectiveness of teaching a low-income population to pasteurize their water - that is, heating water to sub-boiling temperatures to inactivate pathogens by using a thermosensitive indicator [23]. Relative to boiling, pasteurization is a less time-consuming procedure and reduces the risks and potential costs associated with boiling. Among reported users in the Kenyan study, pasteurization reduced the prevalence of microbial contamination of drinking water by over $30 \%$ and the incidence of severe diarrhoea by $45 \%$ relative to individuals who drank untreated water. No other research has been conducted to assess the effect of pasteurization indicator use on household drinking-water safety.

In rural Peru, $70 \%$ of households report boiling [24], yet one investigation documented that $95 \%$ of household drinking-water samples contained microbiological contamination [25], which suggests that the effectiveness of the practice is sub-optimal. We evaluated whether two simple technological interventions - an improved storage container and a water pasteurization indicator - were effective in reducing faecal contamination of household drinking water in a rural Peruvian population that boils drinking water.

\section{METHODS}

\section{Study design}

We conducted an unblinded randomized controlled trial, assigning households in a 1:1:1 ratio to one of two intervention groups or to a control group. The trial was conducted between January and April 2014.

\section{Study setting}

The study was conducted in Humay district, Pisco province, on Peru's southern coast. The district is located in the Pisco River Valley and has a population of 5800 inhabitants. It receives $\sim 2 \mathrm{~mm}$ of rainfall annually. The majority of households use piped drinking-water sources. Water distributed by piped systems either flows directly from the Pisco River, or indirectly through irrigation channels. The piped system of one community distributes water from a borehole. In some communities, the water from piped water systems passes through a sand or gravel filter before distribution. A member of the community water board manually chlorinates piped water stored in elevated tanks before distribution in the two largest communities; this is done on an intermittent basis due to an inconsistent supply of chlorine and lack of availability of the person responsible for chlorination. Because piped water is available between 2 and $20 \mathrm{~h}$ a day, many households pump water into elevated tanks above their homes in order to be able to use it outside of normal service hours.

\section{Sample size}

The sample size was calculated to detect a $15 \%$ relative reduction in the prevalence of Escherichia coli contamination in household drinking water between each of the intervention arms compared to the control arm with $95 \%$ confidence (with respect to two-sided test) and $80 \%$ power, assuming a total number of six follow-up microbiological tests of stored drinking water per household, and an estimated $88 \%$ prevalence of $E$. coli contamination in stored drinking water, $20 \%$ loss to follow-up, and a design effect of 2 . The prevalence of $E$. coli contamination was estimated using pilot data collected from the study district in 2010. The design effect was included to account for the correlation between observations collected from the same household. We aimed to enrol 70 subject households per arm to ensure sufficient power to detect this difference based on these assumptions.

\section{Participants and enrolment}

As described previously [26], households were eligible to participate in the study if they contained a woman aged $\geqslant 18$ years, a child aged $<5$ years, and were able 
to heat water in their home. Field teams conducted a census of the district before the study to identify eligible households. A computerized pseudo-random number generator was used to create a randomly ordered list of eligible houses for recruitment. Using a geographically organized list of eligible households, enumerators enrolled households to participate until a total of 210 was reached; households were randomly assigned to one of the three study groups. If a female head of household was not available at the initial visit, field workers made one additional attempt to enrol the household. Only the female head of household was enrolled for each house and she was the only household member requested to complete study procedures. All participants provided written informed consent before initiation of any study procedures.

At the enrolment visit, a baseline survey was administered to assess participant demographic characteristics; socioeconomic status; household water supply, treatment, storage, and handling behaviours; sanitation and hygiene; presence of a handwashing station (defined as a designated place for handwashing with a water supply and soap present); and ability to demonstrate correct handwashing technique (lathering all surfaces of the hands with soap). A socioeconomic index was generated using principal component analysis of household assets, building materials, and home ownership [27]. The index was comprised of the first principal component of each variable [28] and households were grouped into index terciles for analysis. Field workers used an orthotolidine (OTO) pool test kit (Pentair, USA) to test household source and stored drinking water for the presence of total chlorine. Source and stored household water samples were collected in sterile bottles and analysed for $E$. coli using the Compartment Bag Test (Aquagenx, USA); this test is a highly sensitive and specific qualitative measure [29] and has a minimum threshold of detection of 1 E. coli/100 $\mathrm{ml}$ [30]. Samples were transported in coolers containing ice packs to the study centre and processed within $6 \mathrm{~h}$ of collection. All samples were incubated for a minimum of $20 \mathrm{~h}$ at $35-44.5^{\circ} \mathrm{C}$ [30]. Positive and negative controls were incubated daily with the samples to verify the correct functioning of the tests.

\section{Randomization and study interventions}

The randomization list of eligible houses was computergenerated by the principal investigator (K.H.). Simple randomization was used to assign eligible households to study groups. The group assignments were concealed from the field team enrolling participants until completion of the baseline survey. At that time, the field team phoned the principal investigator, who opened the opaque sealed envelope containing the group assignment that corresponded to the household and communicated the assignment. At the end of the enrolment visit, all participants were informed of the dangers of drinking untreated water. Participants were randomly assigned to one of three groups. Study group A received a locally available 20-1 storage container with a tight-fitting lid and spigot (which we will refer to henceforth as an 'improved container'; Reyplast, Peru); study group B received an improved container and a water pasteurization indicator (Solar Cookers International, USA; Fig. 1) with written and pictorial instructions for its use. The indicator consists of a wax that melts at the pasteurization temperature of $65^{\circ} \mathrm{C}$ in a polycarbonate tube connected to a stainless steel cable that is used to dip the indicator tube into the container in which water is being heated. Two key advantages of indicator use described in the manufacturer's instructions - fuel and time savings - were highlighted in the instructions distributed to participants. Field workers additionally performed a short demonstration of how to use the indicator to pasteurize water and asked the study participant to demonstrate correct use of the indicator in order to ensure understanding. If the participant did not initially demonstrate correct use of the indicator, the field worker reinforced training until the participant could perform the demonstration correctly. Training in indicator use was only conducted once and was not reinforced during the follow-up period. The indicators were reusable and participants were instructed to use the indicator every time they wanted to treat their drinking water. Study group $\mathrm{C}$ received no additional intervention and served as a control group. Participants who received an intervention were asked to use it during the course of the study for their household drinking water.

\section{Outcome assessment}

The primary outcome was the presence of detectable E. coli contamination in stored drinking water. Follow-up home visits began 3 weeks following enrolment and were conducted every 2 weeks over a 10-week period, yielding a total of six possible followup visits and 13 weeks follow-up. At each visit, source and stored household water samples were collected and analysed for $E$. coli using the Compartment Bag Test following the same procedures as described for the enrolment visit. 


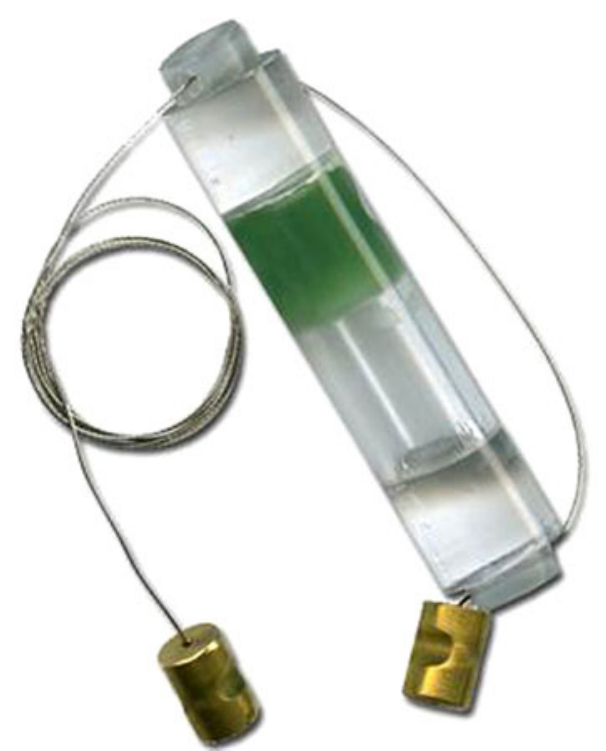

Fig. 1. Water pasteurization indicator (reproduced with permission from www.gofastandlight.com).

\section{Adherence and other measures}

Field workers completed a short survey at all followup visits to assess cooking practices, reported and observed chlorination of source and stored water, and a proxy measure of boiling behaviour (observation of water in a pot on a stove or open fire). In the control group, water storage practices were also observed. In both intervention groups, field workers evaluated use of the improved container (defined as observation of water in the container), and the condition of the container. Participants in study group B were asked to demonstrate and explain how they use their indicator. Correct indicator use was defined as proper indicator tube placement (wax end of tube pointed upward) in a container of water being heated, along with the knowledge to stop heating water when the wax falls to the bottom of the tube. We could not directly assess indicator use because we lacked the resources to do structured observations and, because the indicator tubes were reusable, no used or discarded tubes could be observed. At the final visit, open-ended questions regarding the advantages and disadvantages of the interventions were administered to participants assigned to groups $\mathrm{A}$ and $\mathrm{B}$.

\section{Statistical analysis}

Data were entered into Microsoft Access 2010 (Microsoft Corp., USA) and analysed using Stata v. 13.1 (StataCorp., USA). Cross-tabulations were used to examine the distribution of baseline characteristics by randomization assignment. We used generalized estimating equations (GEE) with a log link function, binomial distribution, working exchangeable correlation structure to account for correlation between repeated measures collected from the same household, and robust standard errors to compare the prevalence of $E$. coli contamination between paired source and stored water samples. As our primary analysis, we used an intention-to-treat approach to assess the effect of the interventions on $E$. coli contamination. The prevalence ratios (PRs) of E. coli contamination were estimated using a GEE model with the same specifications as above. We assessed the sensitivity of these results to possible confounding caused by imbalances in the baseline demographic and socioeconomic characteristics of the randomization groups and or by imbalances in potentially confounding follow-up variables (E. coli contamination of source water, source water chlorination, and type of cooking stove). Substantial confounders were defined as variables that altered the PR estimates by $\geqslant 10 \%$ in adjusted models. The characteristics of participants who adhered to improved container use (had water in the container at $\geqslant 4$ follow-up visits) were evaluated using $\chi^{2}$ and Fisher's exact tests, with Fisher's exact tests being used when any cell contained $<5$ observations [31]. The prevalence of E. coli contamination in stored water was compared between participants who were and were not adherent to container use within each intervention arm using GEE to adjust for household-level clustering.

\section{Ethical considerations}

This study protocol was approved by the Institutional Review Boards of the University of Washington, the U.S. Naval Medical Research Unit No. 6 (NAMRU-6), and the Ica Regional Ministry of Health. Written informed consent was obtained from all subjects and all subject personal identifiers were irreversibly removed from electronic databases following the end of data collection.

\section{RESULTS}

\section{Participants}

Field teams invited a total of 333 households to participate and 210 were enrolled and randomized (Fig. 2). Of the 123 households that were not enrolled, 


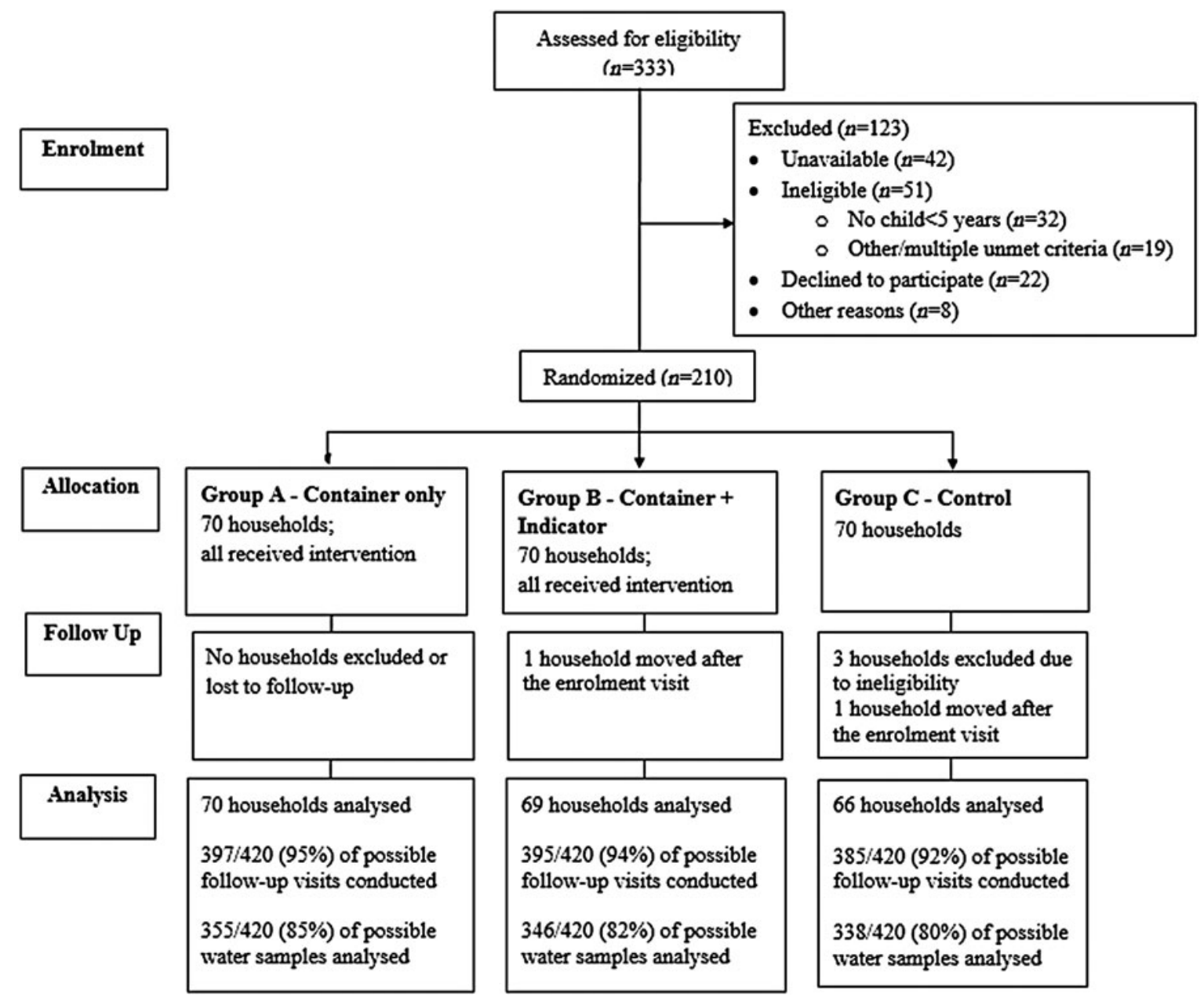

Fig. 2. Trial profile.

the most common reasons for non-participation were not being available at two attempts to enrol (34\%), not having a child aged $<5$ years $(26 \%)$, and refusal to participate $(18 \%)$. The geographical distribution of households did not differ by enrolment status $(P$ $=0.65$ ). The baseline characteristics of eligible participants randomized to each of the three study groups were similar (Table 1). At baseline, E. coli was detected in $42.5 \%$ of stored water samples; chlorine was not detected in any stored water samples. Three participants were excluded from analysis postrandomization due to failure to meet study eligibility criteria. Two participants moved following the enrolment visit, resulting in a total of 205 participants who provided follow-up data for analysis.

Overall, 59\% of households used a water source that was piped to the home, $34 \%$ used an improved source not piped to the home (primarily community standpipes), and $7 \%$ used an unimproved source. Nearly all participants $(98 \%)$ reported treating their household drinking water, with $99 \%$ of those doing so by boiling and $1 \%$ using both boiling and chlorination. When asked an open-ended question regarding the definition of boiling, $194(96 \%)$ of the participants who reported boiling provided a response consistent with adequate heating for water disinfection. Eightynine per cent of participants stored their drinking water in a wide-mouthed container; $11 \%$ used a teapot. Storage containers were observed to be covered at $94 \%$ of enrolment visits. Thirty per cent of households dipped a hand or an object to extract water from the container.

\section{$E$. coli contamination of stored drinking water}

During the follow-up period, the percentages of paired stored and source water samples contaminated by E. coli were similar in group A (storage container only) and group $\mathrm{C}$ (the control group; $P$ values from GEE models $>0 \cdot 13$ ). In group $B$ (storage container 
Table 1. Household demographic, socioeconomic, water, sanitation, and hygiene characteristics by study arm, Pisco, Peru, 2014*

\begin{tabular}{|c|c|c|c|c|}
\hline & $\begin{array}{l}\text { Total } \\
(N=207)\end{array}$ & $\begin{array}{l}\text { Container only } \\
(N=70)\end{array}$ & $\begin{array}{l}\text { Container }+ \text { indicator } \\
(N=70)\end{array}$ & $\begin{array}{l}\text { Control } \\
(N=67)\end{array}$ \\
\hline Median age, years (range) & $31(18-64)$ & $32(19-62)$ & $31(19-56)$ & $31(18-64)$ \\
\hline Median household size (range) & $4(2-15)$ & $4(3-8)$ & $4(2-13)$ & $5(3-15)$ \\
\hline Completed secondary school or above & $117(56 \cdot 5 \%)$ & $37(52 \cdot 9 \%)$ & $42(60 \cdot 0 \%)$ & $38(56 \cdot 7 \%)$ \\
\hline \multicolumn{5}{|l|}{ Socioeconomic index } \\
\hline Poorest tercile & $66(33 \cdot 3 \%)$ & $24(34 \cdot 8 \%)$ & $24(37 \cdot 5 \%)$ & $18(27 \cdot 7 \%)$ \\
\hline Middle tercile & $66(33 \cdot 3 \%)$ & $24(34 \cdot 8 \%)$ & $22(34 \cdot 4 \%)$ & $20(30 \cdot 8 \%)$ \\
\hline Wealthiest tercile & $66(33 \cdot 3 \%)$ & $21(30 \cdot 4 \%)$ & $18(28 \cdot 1 \%)$ & $27(41 \cdot 5 \%)$ \\
\hline \multicolumn{5}{|l|}{ Primary water source } \\
\hline Piped to the home & $120(58 \cdot 8 \%)$ & $44(63 \cdot 8 \%)$ & $40(57 \cdot 1 \%)$ & $36(55 \cdot 4 \%)$ \\
\hline Improved source outside the home & $70(34 \cdot 3 \%)$ & $18(26 \cdot 1 \%)$ & $24(34 \cdot 3 \%)$ & $28(43 \cdot 1 \%)$ \\
\hline Unimproved source & $14(6 \cdot 9 \%)$ & $7(10 \cdot 1 \%)$ & $6(8 \cdot 6 \%)$ & $1(1 \cdot 5 \%)$ \\
\hline E. coli detected in stored water & $85(42 \cdot 5 \%)$ & $27(40 \cdot 3 \%)$ & $29(41 \cdot 4 \%)$ & $29(46 \cdot 0 \%)$ \\
\hline Detectable chlorine in source water & $9(5 \cdot 3 \%)$ & $1(1 \cdot 6 \%)$ & $3(5 \cdot 1 \%)$ & $5(10 \cdot 0 \%)$ \\
\hline Thinks water is safe to drink & $82(39 \cdot 8 \%)$ & $31(44 \cdot 3 \%)$ & $23(33 \cdot 3 \%)$ & $28(41 \cdot 8 \%)$ \\
\hline \multicolumn{5}{|l|}{ Storage container type } \\
\hline Teapot & $22(10 \cdot 8 \%)$ & $10(14 \cdot 9 \%)$ & $7(10 \cdot 0 \%)$ & $5(7 \cdot 6 \%)$ \\
\hline Wide-mouthed container & $181(89 \cdot 2 \%)$ & $57(85 \cdot 1 \%)$ & $63(90 \cdot 0 \%)$ & $61(92 \cdot 4 \%)$ \\
\hline Covered storage container & $194(94 \cdot 2 \%)$ & $65(92.9 \%)$ & $66(94 \cdot 3 \%)$ & $63(95 \cdot 5 \%)$ \\
\hline Clean storage container & $195(94 \cdot 7 \%)$ & $67(95 \cdot 7 \%)$ & $65(92.9 \%)$ & $63(95 \cdot 5 \%)$ \\
\hline \multicolumn{5}{|l|}{ Method of water extraction } \\
\hline Poured/used a spigot & $138(70 \cdot 4 \%)$ & $49(71 \cdot 0 \%)$ & $48(72 \cdot 7 \%)$ & $41(67 \cdot 2 \%)$ \\
\hline Dipped with an object/hands & $58(29 \cdot 6 \%)$ & $20(29 \cdot 0 \%)$ & $18(27 \cdot 3 \%)$ & $20(32 \cdot 8 \%)$ \\
\hline Boiled currently stored water & $194(94 \cdot 6 \%)$ & $66(95 \cdot 7 \%)$ & $65(92.9 \%)$ & $63(95 \cdot 5 \%)$ \\
\hline Toilet/latrine & $167(81 \cdot 1 \%)$ & $57(82 \cdot 6 \%)$ & $57(81 \cdot 4 \%)$ & $53(79 \cdot 1 \%)$ \\
\hline Presence of a handwashing station & $131(63 \cdot 6 \%)$ & $47(67 \cdot 1 \%)$ & $42(60 \cdot 0 \%)$ & $42(63 \cdot 6 \%)$ \\
\hline Correct handwashing & $167(91 \cdot 3 \%)$ & $58(93 \cdot 5 \%)$ & $55(90 \cdot 2 \%)$ & $54(90 \cdot 0 \%)$ \\
\hline
\end{tabular}

* Numbers may not sum to total due to missing values.

plus indicator), stored water samples were less likely to be contaminated than their paired source water samples $(P=0 \cdot 048)$. In group C, $37 \cdot 3 \%$ of stored water samples contained detectable E. coli, compared to $38.3 \%$ in group $\mathrm{A}$, and $44 \cdot 2 \%$ in group $\mathrm{B}$; these differences were not statistically significant $(P$ values for pairwise comparisons in GEE models $>0 \cdot 19$ ). The PR of E. coli contamination relative to group $\mathrm{C}$ was 1.02 [95\% confidence interval (CI) $0 \cdot 79-1 \cdot 31]$ for group A and $1.18(95 \%$ CI $0.92-1.52)$ for group B (Table 2). There was no evidence of confounding of these estimates by demographic or socioeconomic factors or potentially confounding follow-up variables. The prevalence of $E$. coli contamination in group $\mathrm{C}$ was similar during baseline and follow-up visits $(P=0 \cdot 14)$.

There was no trend in the prevalence of contamination of stored water over time in any of the study groups (all $P$ values $>0 \cdot 12$; Fig. 3). E. coli was detected in at least one follow-up visit for 167 (81\%) of 205 households; of the 91 households with complete follow-up data, one household (1\%) had contaminated drinking water at all six follow-up visits; ten households $(11 \%)$ had no E. coli detected in stored drinking water at any of the follow-up visits, and these households were roughly equally distributed among the three study groups.

\section{Adherence to interventions and control group practices}

In the intervention groups, improved containers were observed at $97 \%$ of follow-up visits and were observed to have water inside at $55 \%$ and $58 \%$ of the follow-up visits in study groups $\mathrm{A}$ and $\mathrm{B}$, respectively. Container usage decreased over time in both intervention groups ( $P$ values of GEE models $<0 \cdot 01$ ); about $50 \%$ of households in both intervention arms were using their storage container at the final visit (Fig. 4). The indicator was observed at $90 \%$ of visits; four participants lost their indicator during the follow-up period. Knowledge of correct indicator use was demonstrated by over $90 \%$ of participants during each bi-weekly follow-up period (Fig. 4). 
Table 2. Effect of interventions on the mean prevalence of Escherichia coli contamination of stored drinking water in Pisco, Peru, 2014

\begin{tabular}{llllll}
\hline \hline Study arm & & Observation days with & Risk difference & & \\
relative to control & PR & $(95 \% \mathrm{CI})$ \\
\hline Control & Observation days & E. coli contamination $(\%)$ & $1 \cdot 00$ & $($ Ref.) \\
Container only & 338 & $126(37 \cdot 3)$ & Ref & $1 \cdot 0$ & $(0 \cdot 79-1 \cdot 31)$ \\
Container and indicator & 355 & $136(38 \cdot 3)$ & $6 \cdot 9$ & $1 \cdot 18$ & $(0 \cdot 92-1 \cdot 52)$ \\
\hline \hline
\end{tabular}

PR, Prevalence ratio; CI, confidence interval.

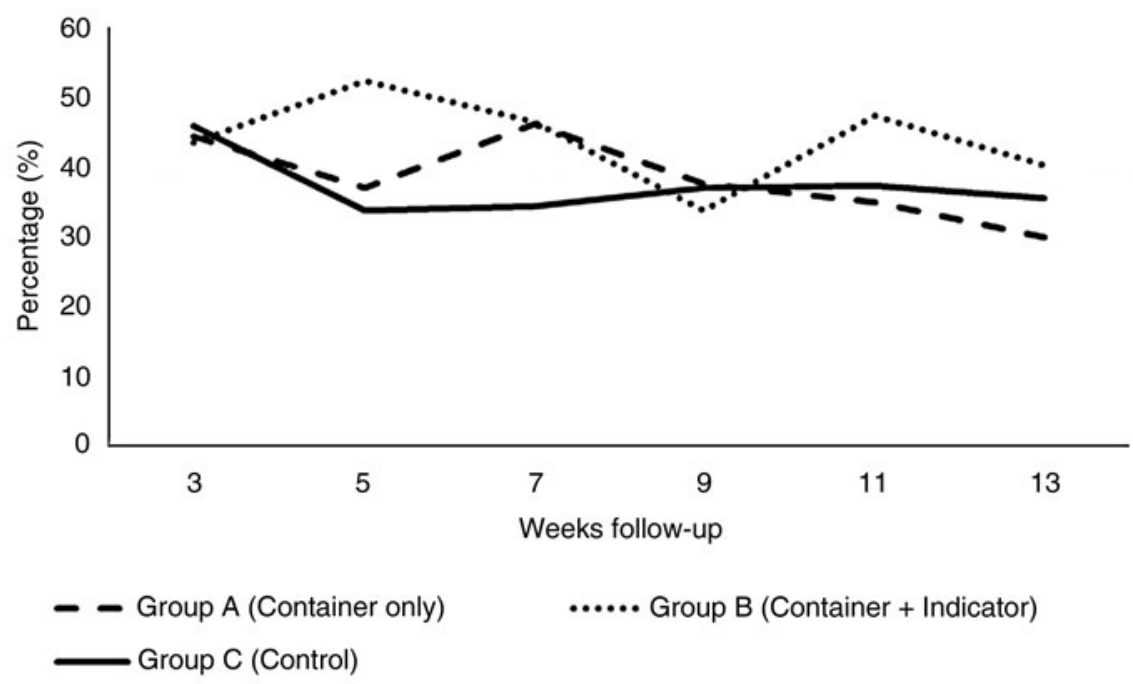

Fig. 3. Percentage of stored drinking-water samples contaminated by Escherichia coli, by study arm and follow-up visit round, Pisco, Peru, January-April 2014.

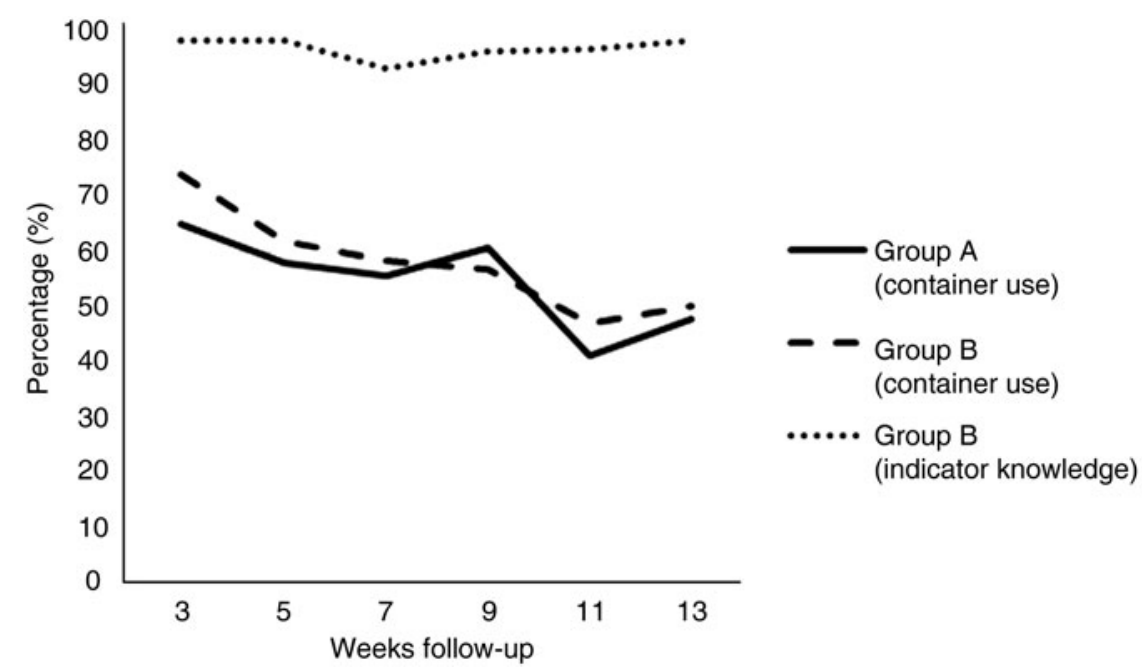

Fig. 4. Percentage of intervention group A and B participants using improved storage container, and intervention group B participants with knowledge of proper indicator use, by follow-up visit round, Pisco, Peru, January-April 2014. 
Table 3. Mean prevalence of Escherichia coli contamination of stored drinking water by adherence with improved storage container use, Pisco, Peru, 2014

\begin{tabular}{llllllll}
\hline \hline & \multicolumn{2}{l}{ Adherent } & & \multicolumn{2}{l}{ Non-adherent } & \\
\cline { 2 - 3 } Study arm & $\% E$ c coli contamination & $(95 \% \mathrm{CI})$ & & $\%$ E. coli contamination & $(95 \% \mathrm{CI})$ & $P$ \\
\hline Container only & $43 \cdot 5$ & $(36 \cdot 2-52 \cdot 3)$ & & $33 \cdot 6$ & $(25 \cdot 4-44 \cdot 5)$ & $0 \cdot 13$ \\
Container and indicator & $48 \cdot 2$ & $(38 \cdot 8-59 \cdot 9)$ & $42 \cdot 9$ & $(34 \cdot 0-53 \cdot 3)$ & $0 \cdot 48$ \\
\hline \hline
\end{tabular}

CI, confidence interval.

About half $(48 \%)$ of participants in both intervention groups adhered to use of the improved storage container (defined as use at $\geqslant 4$ visits). Adherent participants were more likely to have an off-premises water source (not piped directly to the participant's home, yard, or plot; $54 \%$ vs. $27 \%, P=0.002$ ). No other baseline variables were associated with adherence. In both intervention groups, participants who adhered to improved container use had similar stored water quality as participants who used their containers less frequently (Table 3).

In group $\mathrm{C}$ (the control group), the storage container was covered less frequently during the followup period, but prevalence of container coverage was still high $(86 \%$ of the follow-up visits vs. $95 \%$ of baseline visits; $P=0.003$ ). Water was observed in a pot on the stove or open fire at $36 \%$ of visits in group C; this indicator of boiling was observed with similar frequency in group A (36\%) and group B (32\%).

\section{Perceptions of the interventions}

When asked to cite the advantages and disadvantages, if any, of the safe-storage container, participants in groups $\mathrm{A}$ and $\mathrm{B}$ most frequently stated that it was easy to use $(53 \%)$, it made the water safer for drinking $(42 \%)$, and allowed them to store water in larger quantities $(31 \%)$. The most frequently cited disadvantage was that the container was too large $(3 \%)$. Group B participants reported that the primary advantages of using the indicator were saving fuel $(83 \%)$, saving time $(29 \%)$, and ease of use $(28 \%)$. Disadvantages included difficulty of use (3\%) and needing to keep an eye on the indicator to use it correctly (3\%).

\section{DISCUSSION}

Although the results of this trial demonstrated the feasibility of teaching a low-income population to pasteurize their household drinking water via the use of a thermosensitive indicator, this intervention had no significant effect on the risk of $E$. coli contamination of household drinking water. This study is the first to test the effect of use of a water pasteurization indicator in a population in which water boiling was a culturally accepted practice. In the only previous study of a similar intervention, indicator users were compared to individuals who drank untreated water [23]. We found that the provision of an improved storage container had no effect on the prevalence of $E$. coli contamination of household drinking water, which was similar to the result of one previous trial of an improved container [22] but inconsistent with others that demonstrated reductions in indicators of faecal contamination [19-21].

The lack of effect of the pasteurization indicator intervention could be explained in several ways. First, despite retaining knowledge of how to use the indicators, participants may not have used them. Because the indicators are reusable, we could not verify this hypothesis. Second, participants may have used the indicators and this behaviour may have resulted in more effective treatment, but inconsistency of use prevented any significant reduction in contamination. The observation of the proxy for boiling water in a pot on a stove or fire - at over $30 \%$ of home visits coupled with the significant reduction in contamination from source to stored water in group B supports this hypothesis, although we could not confirm the effectiveness of treatment. We could also not confirm boiling behaviour and our proxy for boiling may have been inaccurate if water was boiled outside of the daytime hours during which field workers conducted the study visits. An alternative explanation for the null effect is that although use of the pasteurization indicator resulted in more effective treatment behaviour, the receipt of an indicator led participants to reduce their investment in other protective behaviours such as handwashing, thus negating the impact of more effective treatment on water quality. The 
effect of the prevalence of an exposure such as a public health intervention on demand for disease prevention - termed prevalence elasticity - has been observed for other health-related outcomes [32], but because we did not assess preventive behaviours including hygiene or safe water handling at follow-up visits, we could not confirm whether this occurred. Unlike the previous study using a water pasteurization indicator intervention [23], we did not employ female community leaders to promote indicator use, nor did we demonstrate the effectiveness of pasteurization in reducing the number of bacterial colonies on an agar plate. It is possible that these two elements were critical in the promotion of indicator use and should be considered in future trials of this intervention in order to increase effectiveness. In group A, generally safe water storage and handling practices and good hygiene in the control group likely limited our ability to detect a benefit of the intervention.

The results of this study demonstrate the challenge of improving boiling and safe water storage in a population in which both practices have been accepted but perhaps inconsistently or ineffectively practised. Although participants generally expressed satisfaction with the container, these stated perceptions likely overstated actual satisfaction due to courtesy bias. Moderate use of the storage container highlighted the importance of identifying interventions that the population perceives as offering a relative advantage over current storage practices to increase the probability of use [33]. Similarly, although most group B participants exhibited knowledge of indicator use and perceived its advantages, we could not confirm indicator use. The lack of effect of the indicator may have reflected lack of use for similar reasons as for the storage container.

This study had two important limitations. First, we based our sample size calculation on the prevalence of $E$. coli contamination in drinking-water samples collected from the same district in 2010, as this was the only relevant data available at the time of protocol development. Although the majority of drinking water from even piped sources in rural Peru is contaminated with $E$. coli [25, 34], progressive expansion of access to piped water infrastructure in the area likely contributed to the unexpectedly low prevalence of contamination in the control group, which limited our ability to detect statistically significant differences. Second, we assessed our primary outcome, E. coli contamination, using the Compartment Bag Test. This test has the advantages of requiring minimal materials or technical skill to perform, but yields imprecise quantitative results [30]. It is, however, a highly sensitive and specific qualitative measure of contamination [29]. A qualitative assessment of $E$. coli contamination may be adequate given that it corresponds with the WHO standard of drinking-water safety [35]. Moreover, the results of a recent systematic review and meta-analysis indicate that while the presence of $E$. coli contamination in drinking water is associated with the risk of diarrhoea, increasing levels of E. coli contamination in drinking water beyond a detectable level did not demonstrate a dose-response relationship with risk [36]. This finding was based on a small number of studies, however, and more research is needed to determine whether a qualitative measure of $E$. coli contamination is sufficient indicator of health risk.

Our study findings indicate that the use of a water pasteurization indicator was not effective in reducing faecal contamination of household drinking water in a population that had already adopted boiling as a method of treatment. However, this investigation and a previous study [23] provided evidence of the feasibility of teaching a low-income population to use a thermosensitive indicator to pasteurize their drinking water. Future research is needed on methods to improve objective measurement of indicator use and assess the impact of this intervention on drinking water safety and diarrhoeal disease in populations at high risk for waterborne disease. Formative research may additionally be useful to better understand the factors that influence use of water treatment and storage interventions designed to limit the contamination of drinking water in the home.

\section{ACKNOWLEDGEMENTS}

We thank the study participants for their contribution to this investigation. This research would not have been possible without the administrative and logistical support of Asociación Benéfica PRISMA, particularly Crisóloga Lauro Salas, Angela Huamán Gómez, Alex Fernández Díaz, Enny Herrera Mayuri, Beatriz Huamán Ccollana, and Aydee Huanaco Muñoz. We additionally thank the Peace Corps Water and Sanitation Programme in Peru, particularly Hilary Miller, for her help throughout this project.

This research was supported by the Department of Defense Humanitarian Assistance Program (project no. 20306) and by NIH research training grant no. R25 TW009345 awarded to the Northern Pacific 
Global Health Fellows Program by the Fogarty International Center.

C. A. Rocha, R. E. Quick, S. M. Montano and D. H. Tilley Jr. are employees of the U.S. Government. This work was prepared as part of their official duties. The findings and conclusions expressed in this manuscript are those of the authors and do not necessarily reflect the official policy or position of the Department of the Navy, Department of Defense, the Centers for Disease Control and Prevention, nor the U.S. government.

\section{DECLARATION OF INTEREST}

None.

\section{REFERENCES}

1. Walker CL, et al. Global burden of childhood pneumonia and diarrhoea. Lancet 2013; 381: 1405-1416.

2. Liu L, et al. Global, regional, and national causes of child mortality in $2000-13$, with projections to inform post-2015 priorities: an updated systematic analysis. Lancet 2015; 385: 430-440.

3. GBD 2013 Mortality and Causes of Death Collaborators. Global, regional, and national age-sex specific allcause and cause-specific mortality for 240 causes of death, 1990-2013: a systematic analysis for the Global Burden of Disease Study 2013. Lancet 2015; 385: 117-171.

4. WHO/UNICEF. Diarrhoea: why children are still dying and what can be done. Geneva: WHO, 2009.

5. Rosa G, Clasen T. Estimating the scope of household water treatment in low- and medium-income countries. American Journal of Tropical Medicine and Hygiene 2010; 82: 289-300.

6. Clasen T. Scaling up household water treatment among low-income populations. Geneva: WHO, 2009.

7. Oswald WE, et al. Fecal contamination of drinking water within peri-urban households, Lima, Peru. American Journal of Tropical Medicine and Hygiene 2007; 77: 699-704.

8. Rufener S, et al. Quality of drinking-water at source and point-of-consumption - drinking cup as a high potential recontamination risk: a field study in Bolivia. Journal of Health, Population, and Nutrition 2010; 28: 34-41.

9. Wright J, Gundry S, Conroy R. Household drinking water in developing countries: a systematic review of microbiological contamination between source and point-of-use. Tropical Medicine and International Health 2004; 9: 106-117.

10. Gilman RH, Skillicorn P. Boiling of drinking-water: can a fuel-scarce community afford it? Bulletin of the World Health Organization 1985; 63: 157-163.

11. Biran A, Abbot J, Mace R. Families and firewood: a comparative analysis of the costs and benefits of children in firewood collection and use in two rural communities in sub-Saharan Africa. Human Ecology 2004; 32: 1-25.

12. Samuel JC, et al. The epidemiology, management, outcomes and areas for improvement of burn care in central Malawi: an observational study. Journal of International Medical Research 2011; 39: 873-879.

13. Mukerji G, et al. Epidemiology of paediatric burns in Indore, India. Burns 2001; 27: 33-38.

14. Rossi LA, et al. Childhood burn injuries: circumstances of occurrences and their prevention in Ribeirao Preto, Brazil. Burns 1998; 24: 416-419.

15. Delgado $\mathbf{J}$, et al. Risk factors for burns in children: crowding, poverty, and poor maternal education. Injury Prevention 2002; 8: 38-41.

16. Smith KR, Mehta S, Maeusezahl-Feuz M. Indoor air pollution from household use of solid fuels. In: Ezzati M, Lopez AD, Roders A, eds. Comparative Quantification of Health Risks, Global and Regional Burden of Disease Attributable to Selected Major Risk Factors. Geneva: World Health Organization, 2004, pp. 1435-1494.

17. Ramanathan $\mathbf{V}$, et al. Warming trends in Asia amplified by brown cloud solar absorption. Nature 2007; 448: 575-578.

18. Jacobson MZ. Strong radiative heating due to the mixing state of black carbon in atmospheric aerosols. Nature 2001; 409: 695-697.

19. Roberts L, et al. Keeping clean water clean in a Malawi refugee camp: a randomized intervention trial. Bulletin of the World Health Organization 2001; 79: 280-287.

20. Gunther I, Schipper Y. Pumps, germs and storage: the impact of improved water containers on water quality and health. Health Economics 2013; 22: 757-774.

21. Ercumen A, et al. Effects of source versus household contamination of tubewell water on child diarrhea in rural Bangladesh: a randomized controlled trial. PLoS ONE 2015; 10: e0121907.

22. Firth $\mathbf{J}$, et al. Point-of-use interventions to decrease contamination of drinking water: a randomized, controlled pilot study on efficacy, effectiveness, and acceptability of closed containers, Moringa oleifera, and in-home chlorination in rural South India. American Journal of Tropical Medicine and Hygiene 2010; 82: 759-765.

23. Iijima Y, et al. Prevention of bacterial diarrhea by pasteurization of drinking water in Kenya. Microbiology and Immunology 2001; 45: 413-416.

24. Instituto Nacional de Estadística e Informática (INEI). Peru: Continuous DHS 2012. In. Calverton, Maryland: Demographic and Health Surveys, 2012.

25. Miranda M, et al. State of the quality of drinking water in households in children under five years in Peru, 2007 2010. Revista Peruana de Medicina Experimental y Salud Publica 2010; 27: 506-511.

26. Heitzinger K, et al. 'Improved' but not necessarily safe: an assessment of fecal contamination of household drinking water in rural Peru. American Journal of Tropical Medicine and Hygiene 2015; 93: 501-508.

27. Vyas S, Kumaranayake L. Constructing socio-economic status indices: how to use principal components analysis. Health Policy and Planning 2006; 21: 459-468. 
28. Houweling TA, Kunst AE, Mackenbach JP. Measuring health inequality among children in developing countries: does the choice of the indicator of economic status matter? International Journal for Equity in Health 2003; 2: 8 .

29. Stauber C, et al. Evaluation of the compartment bag test for the detection of Escherichia coli in water. Journal of Microbiological Methods 2014; 99C: $66-70$.

30. Aquagenx. Compartment Bag Test: instructions for use, 2013.

31. Gaddis GM, Gaddis ML. Introduction to biostatistics: Part 5, Statistical inference techniques for hypothesis testing with nonparametric data. Annals of Emergency Medicine 1990; 19: 1054-1059.
32. Philipson T. Economic epidemiology and infectious diseases. In: Culyer A, Newhouse JP, eds. Handbook of Health Economics. Amsterdam: Elsevier, 2000, pp. 1761-1799.

33. Everett EM. Diffusion of Innovations. New York: Free Press, 2003.

34. Bain R, et al. Fecal contamination of drinking-water in low- and middle-income countries: a systematic review and meta-analysis. PLoS Medicine 2014; 11: e1001644.

35. WHO. Guidelines for drinking water quality. Geneva: WHO, 2011 (4th series).

36. Gruber JS, Ercumen A, Colford Jr. JM. Coliform bacteria as indicators of diarrheal risk in household drinking water: systematic review and meta-analysis. PLoS ONE 2014; 9: e107429. 